Submission ID: 43746

\title{
Lithological Characterization of Khadum Formation Sections in East
}

Caucasian Region

O.V. Sivalneva (Gubkin Russian State University of Oil and Gas), N.A. Osintseva (Gubkin Russian State University of Oil and Gas), A.V. Postnikov (Gubkin Russian State University of Oil and Gas), Y.E. Varov* (Gubkin Russian State University of Oil and Gas), V.V. Poshibaev (Gubkin Russian State University of Oil and Gas), M.R. Ganaeva (Gubkin Russian State University of Oil and Gas), A.D. Musikhin (Gubkin Russian State University of Oil and Gas), A.S. Rakhmatullina (Gubkin Russian State University of Oil and Gas)

\section{SUMMARY}

Recently North Caucasian Oil and Gas Province is one of the perspective areas for hydrocarbon reserves replenishment. As regards, unconventional perspective objects in Khadum and Batalpashinskiy deposits are new targets for exploration and development. That is why lateral heterogeneity of deposits and reservoir model are crucial work issues. In this purpose, a series of lithological and sedimentological investigations carried out. Based on obtained results lithological characterization of Khadum formation sections was build. In addition, there was conducted a comparison for two structural zones - East Stavropol Depression and Prikuma Uplifting Zone 

Предкавказья

Варов Ю.Е. ${ }^{*}$, Сивальнева О.В. ${ }^{1}$, Осинцева Н.А. ${ }^{1}$, Постников А.В. ${ }^{1}$, Пошибаев В.В. ${ }^{1}$, Ганаева М.Р. ${ }^{1}$, Мусихин А.Д. ${ }^{1}$ Р Рахматуллина А.С. ${ }^{1}(1$ - РГУ нефти и газа (НИУ) им. И.М. Губкина)

\section{Введение}

В настоящее время территория Северо-Кавказской НГП является одной из перспективных с точки зрения пополнения ресурсной базы углеводородов. Новым направлением в этом отношении является проведение геологоразведочных работ для выделения и картирования нетрадиционных перспективных объектов в отложениях нижнемайкопской серии - хадумской и баталпашинской свит, а также определение подходов к разработке таких объектов. Важным вопросом при этом является определение модели коллектора, строения разрезов и выявление закономерностей изменения свойств отложений по площади.

С этой целью был проведен комплекс литолого-седиментологических исследований, на основании результатов которого сформирована литологическая характеристика разрезов хадумских отложений и проведено их сопоставление для двух структурных зон - ВосточноСтавропольской впадины и Прикумской зоны поднятий.

\section{Метод}

В хадумских отложениях коллекторы представлены глинистыми и глинисто-карбонатными породами с высоким содержанием органического вещества - до 7\%. Это позволяет рассматривать их также в качестве нефтематеринских пород. Преобладающим является порово-трещинный тип коллекторов. При этом матрица пород обладает очень низкими значениями пористости и именно структурно-вещественные параметры определяют степень неоднородности пород, благоприятную для развития трещиноватости.

Для характеристики пород-коллекторов с различными ФЕС был выбран комплекс литологоседиментологических и геохимических исследований, включающий в себя: макроизучение кернового материала, изучение структуры пород в обычном поляризационном и растровом электронном (РЭМ) микроскопах, определение минералогического состава пород и характеристику органического вещества при помощи рентгенофазового анализа, РЭМ, пиролиза, а также изучение пустотного пространства методом рентгеновской микротомографии.

\section{Примеры}

Хадумские отложения на исследуемой территории подразделяются на три горизонта: нижний Пшехский, средний - «остракодовый» пласт и верхний - горизонт Морозкиной балки.

На основании результатов изучения кернового материала 27 скважин установлено, что отложения Пшехского горизонта представлены преимущественно карбонатно-глинистыми породами и - в меньшем количестве - аргиллитами тонкослоистыми.

Карбонатно-глинистые породы (Рисунок 1) сложены глинистым материалом гидрослюдистого состава с относительно равномерным распределением карбонатного материала (кальцита, сидерита), иногда формирующего линзовидные скопления. Присутствует органогенный детрит в виде раковин фораминифер Globigerina, фосфатизированных остатков - рыбной чешуи и костей, реже - обломков раковин остракод. Количество терригенной примеси (обломков кварца и слюд) не превышает 1-2\%. Органическое вещество распределено относительно 
равномерно и его количество достигает $6 \%$ от массы пород. Породы характеризуются низкими значениями пористости - в среднем до 6\%. Пустотное пространство представлено преимущественно изолированными округлыми пустотами глинистой матрицы размером 5-10 мкм (Рисунок 2).
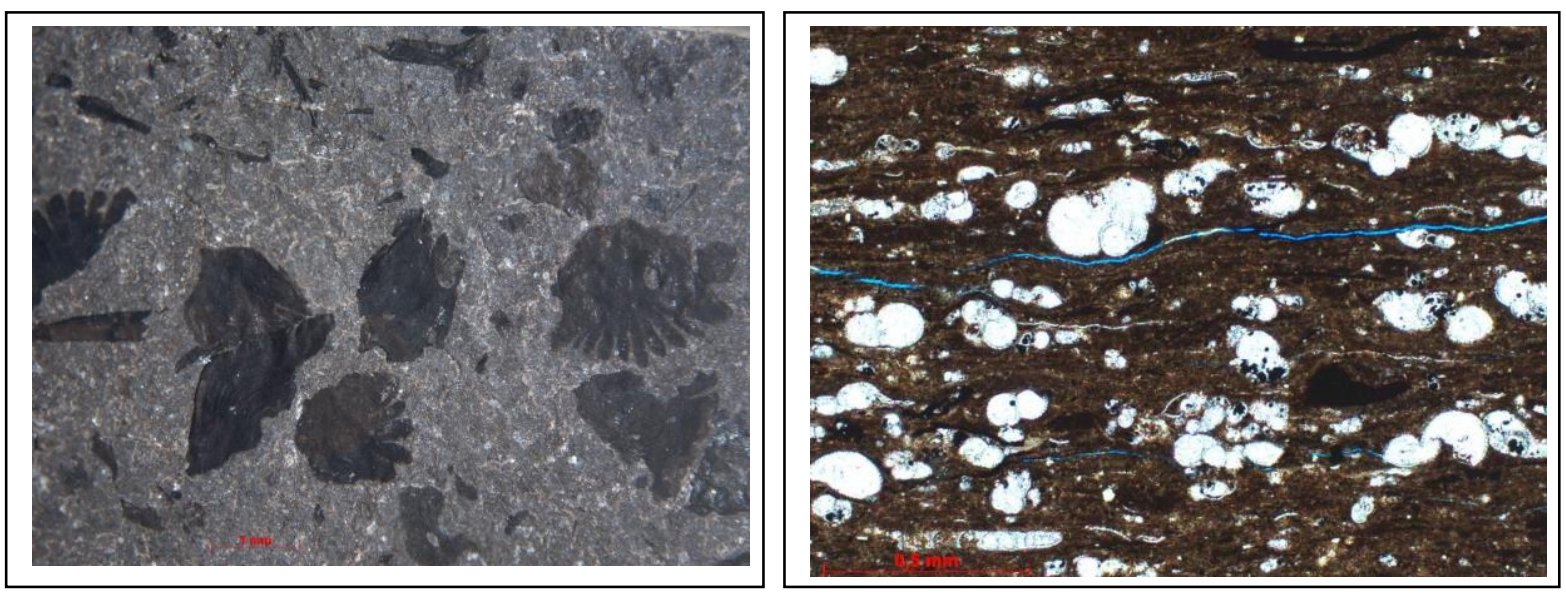

Рисунок 1 Многочисленные остатки чешуи рыб. Фото породы в стереоскопе (слева). Относительно равномерное распределение ОВ в карбонатно-глинистой массе. Кальцитизированные раковины Globigerina. Фото шллифа без анализатора (справа)
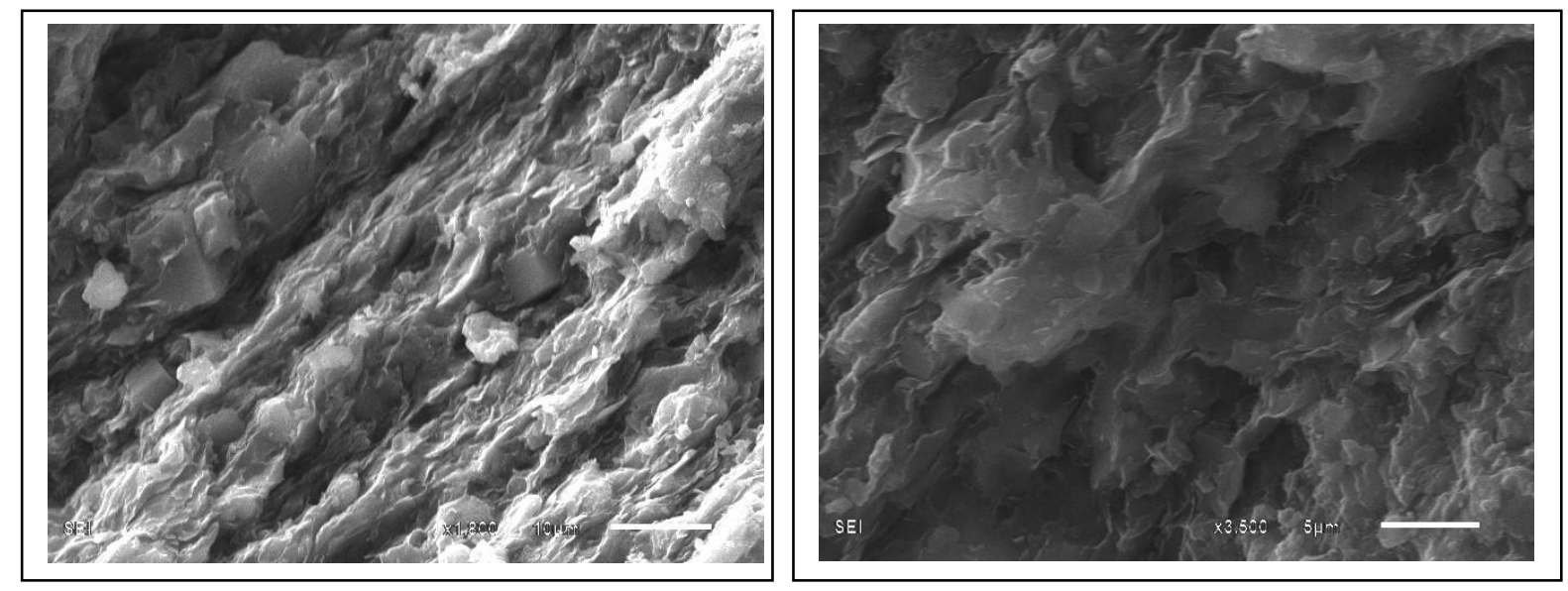

Рисунок 2 Кристалль кальиита в глинистой массе. Ячеистая структура пустотного пространства в карбонатно-глинистой массе. Фото образияв в РЭМ.

В верхней части хадумской свиты (горизонт Морозкиной балки) преобладают аргиллиты тонкослоистые (Рисунок 3), сложенные глинистым материалом гидрослюдистого состава с примесью кремнистого, карбонатного материала и органического вещества, которые образуют единую структуру породы. Отмечается незначительное количество органогенного детрита и алевритовой примеси (до 3\%). Количество органического вещества достаточно высокое - Сорг $2-6 \%$. ОВ в породе концентрируется в линзах и прослоях, подчеркивая тонкую горизонтальную слоистость и неоднородность пород. Пустотное пространство аргиллитов тонкослоистых представлено двумя типами - порами и открытыми трещинами. Поры представляют собой округлые (2-10 мкм) и щелевидные пустоты (10-50 мкм) в глинистой массе (Рисунок 4). По результатам рентгеновской микротомографии породы характеризуются низкими значениями пористости 1-8,5\%. Преобладают поры эффективного диаметра 5-25 мкм. Коэффициент связанности пор определяется как очень низкий (0,38-1,9\%) и низкий (6-11\%). Это указывает на то, что возможность формирования коллекторов в таком типе пород напрямую зависит от развития трещиноватости для обеспечения связанности пор. 


\section{EAGE}
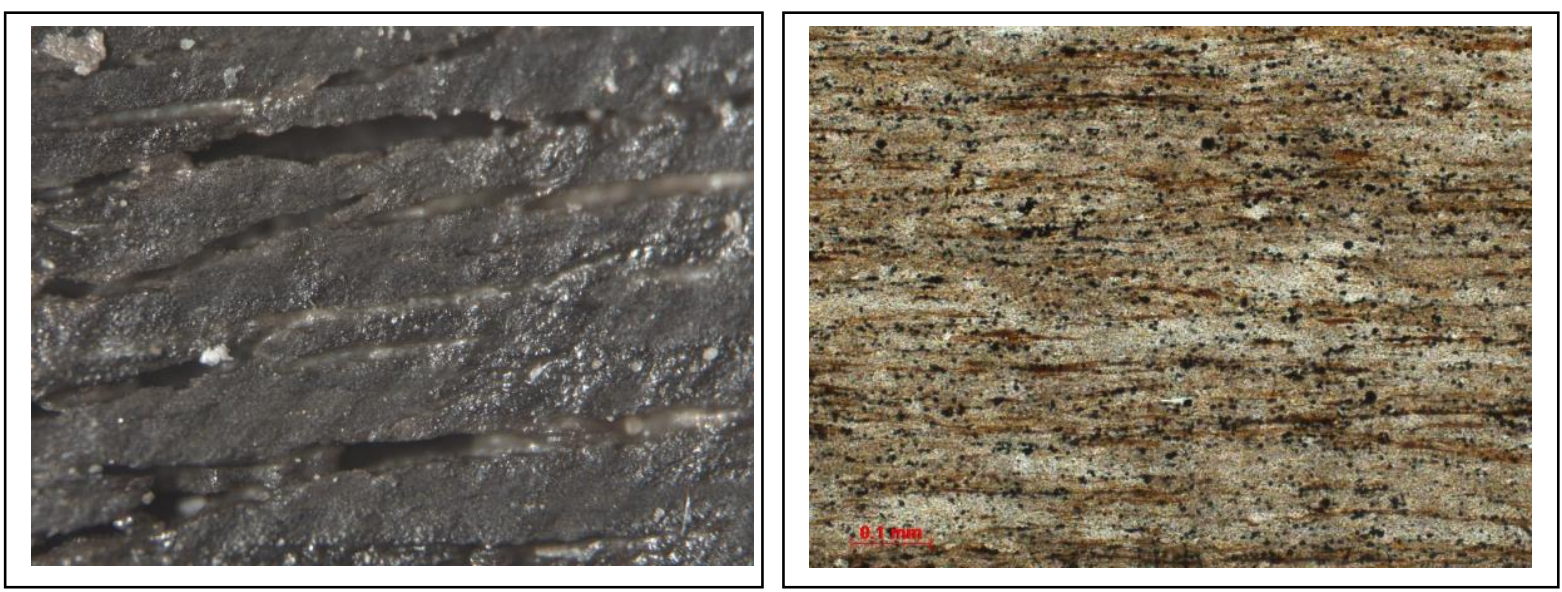

Рисунок 3 Субгоризонтальные трещины в аргиллите тонкослоистом. Фото породы в стереоскопе (слева). Тонкослоистая структура аргиллита за счет прослоек органического вещества. Фото шлифа без анализатора (справа)
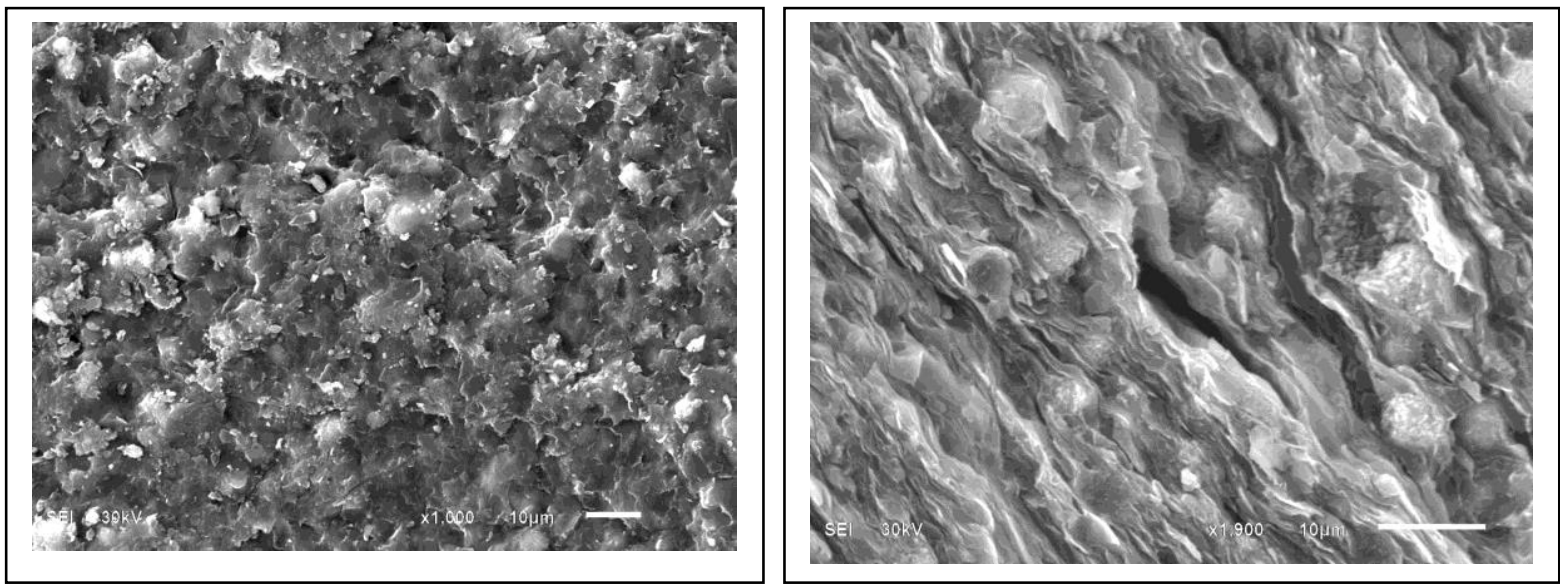

Рисунок 4 Микропористость глинистой массы, срез по плоскости наслоения. Щелевидные пустоты, глобули пирита, срез перпендикулярно плоскости. Фото образиов в РЭМ.

Отложения «остракодового» пласта представлены глинистыми известняками.

Сопоставление разрезов скважин площадей Восточно-Ставропольской впадины и Прикумской зоны поднятий показало, что состав и строение слагающих отложений достаточно похожи. Основные различия заключаются в изменении толщин в западном направлении - наблюдается их уменьшение от Восточно-Ставропольской впадины к Прикумской зоне поднятий. В среднем толщины отложений для Журавского поднятия достигают 80 м (восток), для Прасковейского поднятия - 40-80 м, для Озек-Суатского поднятия - 40 м (запад). Такая изменчивость обусловлена уменьшением толщин интервалов, сложенных аргиллитами тонкослоистыми.

\section{Выводы}

В разрезах отложений Пшехского горизонта хадумской свиты преобладают карбонатноглинистые породы, сложенные карбонатно-глинистым материалом (до 50\%). Органическое вещество присутствует в равномерно рассеянном виде и составляет до $6 \%$ от массы пород. Породы характеризуются низкими значениями пористости (в пределах первых процентов), которая представлена изолированными округлыми пустотами глинистой матрицы размером 510 мкм. В этих породах возможно формирование коллекторов трещинного типа лишь при интенсивном развитии трещиноватости. 
В отложениях горизонта Морозкиной балки преобладают аргиллиты тонкослоистые, сложенные глинистым материалом гидрослюдистого состава с примесью кремнистого, карбонатного материала и органического вещества (ОВ - 2-6\%). ОВ концентрируется в линзах и прослоях, что усиливает структурную неоднородность пород. Пустотное пространство аргиллитов тонкослоистых представлено двумя типами - порами и открытыми трещинами. Поры представляют собой округлые (2-10 мкм) и щелевидные пустоты (10-50 мкм) в глинистой массе. Трещины соединяют имеющиеся пустоты и для этих пород характерно развитие коллекторов порово-трещинного типа.

Отложения хадумской свиты относительно однородны по составу и строению в пределах Восточно-Ставропольской впадины и Прикумской зоны поднятий. Основные различия заключаются в изменении толщин разрезов: по направлению с востока на запад отмечается уменьшение толщин $(80-40$ м) за счет уменьшения толщин интервалов, сложенных аргиллитами тонкослоистыми.

Выявленные особенности позволяют предположить необходимость различных подходов к разработке перспективных площадей на указанных территориях.

\section{Библиография}

Кунин, Н.Я. [1987] Особенности геологического строения и нефтегазоносность нижнемайкопских глинистых отложений Восточного Предкавказья. Обзор. инф. Сер. «Нефтегазовая геология и геофизика». Вып. 5 (112). М.: ВИНИТИ.

Сивальнева, О.В., Осинцева, Н.А., Постников, А.В., Варов, Ю.Е., Пошибаев, В.В., Ганаева, М.P. [2016] Литологическая характеристика и строение разрезов хадумских отложений Восточного Предкавказья. «Геофизика», №6, с. 14-20.

Постников, А.В., Мусихин, А.Д., Осинцева, Н.А., Сивальнева, О.В., Рахматуллина, А.С. [2016] Влияние структуры пустотного пространства пород на разработку залежей в хадумских отложениях Восточного Предкавказья. «Геофизика», №6, с. 30-37.

Мусихин, А.Д., Постников, А.В., Ляпунов, Ю.В., Осинцева, Н.А., Сивальнева, О.В., Рахматуллина, А.С., Антипова, О.А., Сабиров, И.А. [2017] Связь пустотного пространства пород с разработкой залежей УВ в хадумских отложениях Восточного Предкавказья. Тезисы семинара EAGE/SPE 2017 «Наука о сланцах: проблемы разведки и разработки», M07.

\section{References}

Kunin, N.Y. [1987] Osobennosty geologicheskogo stroeniya i neftegazonosnost nignemaykopskih glinistih otlogeniy Vostochnogo Predkavkazya. Obzor. Inf. Ser. "Neftegazovaya geologiya I geophysika”. Vyp. 5 (112). M.: VINITI

Sivalneva, O.V., Osintseva, N.A., Postnikov, A.V., Varov Y.E., Poshibaev, V.V., Ganaeva, M.R. [2016] Lithological characterization and well section structure of Khadum formation in East Caucasian Region. “Geophysics”, №6, pp. 14-20.

Postnikov, A.V., Musikhin ,A.D., Osintseva, N.A., Sivalneva, O.V., Rakhmatullina, A.S. [2016] Influence of rock pore structure on deposits development of Khadum formation in East Caucasian Region. "Geophysics”, №6, pp. 30-37.

Musikhin, A.D., Postnikov, A.V., Lyapunov, U.V., Osintseva, N.A., Sivalneva, O.V., Rakhmatullina, A.S., Antipova, O.A., Sabirov, I.A. [2017] Communication of the Pore Space of Rocks with Exploitation of HC Deposits in the Khadum Sediments of the Eastern Ciscaucasia. EAGE/SPE Joint Workshop 2017. Shale Science: Prospecting \& Development. Extended Abstract, M07 